\title{
Model-Based Predictive Rotor Current Control Strategy for Indirect Power Control of a DFIM Driven by an Indirect Matrix Converter
}

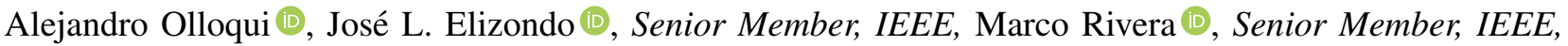 \\ Manuel E. Macías (D, Osvaldo M. Micheloud (D, Senior Member, IEEE, Rubén Peña ${ }^{\circledR}$, Senior Member, IEEE, \\ and Patrick Wheeler (D), Senior Member, IEEE
}

\begin{abstract}
This paper presents a new control strategy using model-based predictive current control (MB-PCC) for a doubly fed induction machine (DFIM) driven by an indirect matrix converter (IMC). This strategy proposes the control of rotor currents, whose references are calculated from active and reactive stator power set points and the dynamic model of the DFIM. The control strategy works well in the four P-Q operating regions of the DFIM. The grid synchronization process is carried out by setting the $P-Q$ power set points to zero. The results include the DFIM synchronization procedure as well as the active and reactive power control at variable shaft speed to validate the feasibility of the proposed strategy.
\end{abstract}

Index Terms-AC/AC power conversion, model-based predictive control (MBPC), doubly fed induction machine (DFIM), indirect matrix converter (IMC), power control, wind energy conversion systems (WECS).

\begin{tabular}{ll} 
& \multicolumn{1}{c}{ NOMENCLATURE } \\
$t_{s}$ & Sampling time \\
Superscripts & \\
$t$ & Variable or quantity referred to stator \\
$T, k, *$ & Transpose, predicted, reference value \\
Subscripts & \\
$s, r$ & Stator, rotor \\
in $, f, g$ & IMC input, filter, grid variable
\end{tabular}

\section{INTRODUCTION}

According to the International Energy Agency, by 2018 the share of electricity generation in the world by renewable and waste sources (including hydro), was on track to reach coal as the main source of electricity, and had already surpassed

This work was supported in part by the Chilean National Research and Development Agency under Grant MEC 80150056, in part by the FONDECYT through the Research Projects under Grants 1160690 and 1191028, in part by the Chilean Solar Energy Research Center, and in part by the Power Electronics Research Group at Universidad de Talca, Curicó Campus, Chile.

A. Olloqui, J. L. Elizondo, M. E. Macías, and O. M. Micheloud are with the School of Engineering and Sciences, Tecnológico de Monterrey, Monterrey Campus, México e-mails: alolm@vestas.com; jl.elizondo.carrales@ieee.org; mmacias@tec.mx; osvaldo.micheloud@tec.mx

M. Rivera is with the Department of Electrical Engineering, Universidad de Talca, Curicó Campus, Chile, e-mail: marcoriv@utalca.cl

R. Peña is with the Department of Electrical Engineering, Universidad de Concepción, Concepción Campus, Chile, e-mail: rupena@udec.cl

P. Wheeler is with the Department of Electrical and Electronic Engineering, University of Nottingham, United Kingdom and China, e-mail: pat.wheeler@nottingham.ac.uk

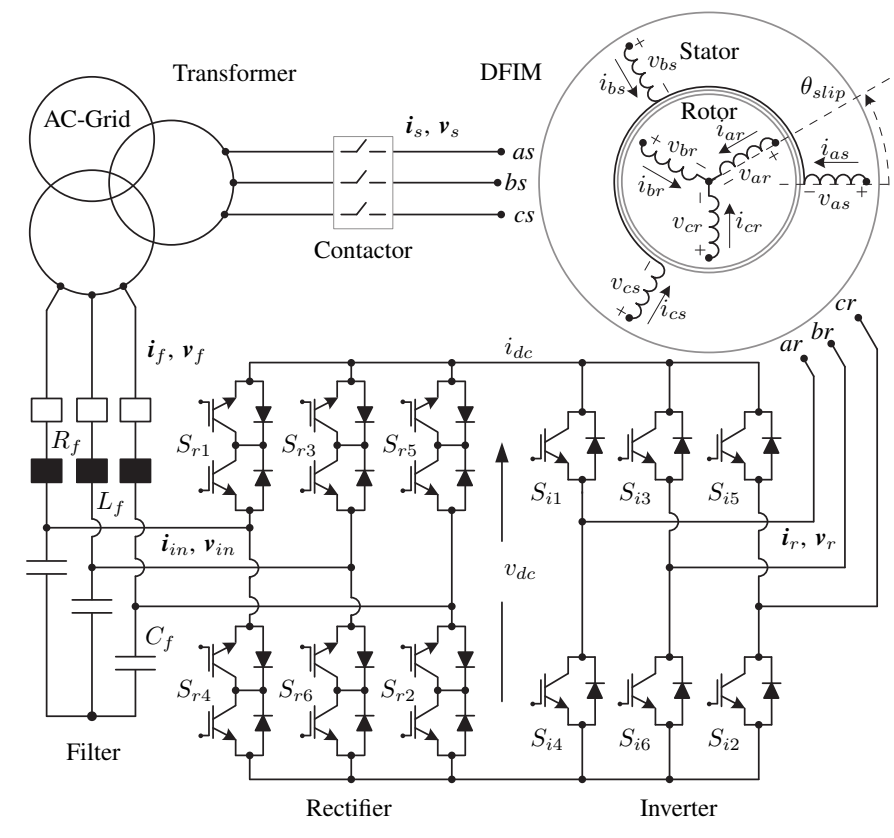

Fig. 1. Wind energy conversion system with DFIM driven by an IMC on the rotor side.

natural gas since 2013 [1]. Together, non-hydro sources such as geothermal, solar, wind, and bio-fuels, grew faster than any other energy source. Moreover, wind energy continues to receive attention within renewable energy sources due to significant government stimulus programs, cost reduction strategies, and technological advancements.

Classified broadly by mechanical, electrical, and control systems, the wind energy conversion systems (WECS) are also known as wind turbine generators (WTG) and are often arranged in groups to form a wind farm on the land (onshore) or on the sea (offshore). Several aerodynamic and electromechanic characteristics of the WTGs have changed in the last 40 years. The diameter of the rotor swept area has increased from $15 \mathrm{~m}$ to $220 \mathrm{~m}$, the nominal power has increased from $50 \mathrm{~kW}$ to $12 \mathrm{MW}$ in 2020 [2], and the driving technology from fixed-speed to full-variable-speed operation over recent years [3], [4].

Two of the main components in the operation of WECS are the electric generator and the power electronic converter. The 
doubly fed induction machine (DFIM) is one of the dominating generator topologies for WECS rated at up to $4 \mathrm{MW}$, with approximately $50 \%$ of the share in today's market [2], [3]. In spite of requiring a gearbox and slip rings that demand regular maintenance, the DFIM presents advantages such as decoupled active and reactive power control, operation on a wide speed range, and principally, a reduced power converter rating when installed at the rotor terminals [5], [6].

The power converter must satisfy the grid requirements, such as the rated voltage and current of the generator, bidirectional power flow, total harmonic distortion among others. The matrix converter (MC) is suitable for the control of variable-speed WECS since it can comply with the mentioned grid requirements. Furthermore, MCs feature sinusoidal input and output currents, high power density, controllable input displacement power factor, lightweight and can operate in environments with harsh temperatures and pressures [7], [8].

The indirect matrix converter (IMC) inherits the suitability and features of MCs to drive a WECS, but with a DC link that makes it easier to control with a more secure current commutation [9]-[11]. The IMC does not have large energy storage elements. The latter enables a compact design but limits the reactive power capability to that of the energy stored in the filter and in the load [12], [13].

Variable-speed WECS require accurate control of the electric torque or machine currents. Many methods have been proposed in the literature to guarantee the stable, secure, and efficient operation of WECS, to maximize energy capture, as well as to comply with fault ride-through capabilities according to continuous grid code updates [14].

Conventional power or torque control techniques for DFIM in WECS can be generally classified as direct or indirect [15]. Indirect control is often related to vector control (VC) and it is characterized by using modulation (e.g. pulse width modulation [16] and space vector modulation [17]) to control the power converter. Direct techniques, such as direct power control (DPC) and direct torque control, establish a direct relation between the controlled variables and the switching states of the converter [18]. VC applied to DFIMs involves relatively complex calculations and requires extra current loops carefully tuned to ensure system performance and stability under the whole operating range [19].

In DPC, the converter's switching states are selected through a table based on the instantaneous errors in the control variables. The key part of DPC implementations is the correct and fast estimation of the WECS power output. The DPC main disadvantage might be the resultant variable switching frequency and excessive power ripple [20]. There are recent works that have proposed predictive DPC with virtual power [21] or virtual torque [22] reference for the synchronization (mode 1) and power regulation (mode 2) of the DFIM in a two-step strategy. Other works have applied predictive control to address unbalanced grid conditions [23]-[25] using conventional converters, and using a MC [26].

A model-based predictive control (MBPC) synchronization strategy for the DFIM was proposed in [11]. There, a simplified DFIM model with an open stator was used, in the $\alpha \beta$ reference frame, achieving the process without the need of any modulation strategy while driven by an IMC.

The selection of an IMC to drive a DFIM in [11] is mainly based on two key characteristics where it has been proven to be better than back-to-back converters: the power density and the power-to-mass ratio [27]. Moreover, the configuration shown in Fig. 1 is intended for both academic research and implementation on remote rural locations for distributed electricity generation where maintenance tasks are difficult to perform.

MBPC has been recognized to be an advanced control method capable of achieving robust results even with the hardest systems' dynamic models. The latter while maintaining a rather simple methodology to always obtain the best switching state of a power converter to deliver optimal results within every sampling time [28]. MBPC has shown significant robustness even with parameters variations or uncertainties along with very fast dynamic responses in AC microgrids [29]. Therefore, MBPC is a very competitive alternative to conventional control schemes for the application described in this work.

This paper proposes an improved model predictive rotor current strategy, when compared to the one in [11], to indirectly control the DFIM active and reactive power, including the synchronization process to the grid, within a single scheme. The latter is easily achieved by initially setting the power references to zero for synchronization and, after closing the stator-grid contactor, applying the required power references to control. The setup is a variable-speed WECS formed by a DFIM driven by an IMC. This strategy controls the DFIM in all four operating regions, MBPC controls the rotor currents with a reference calculated from the dynamic model of the DFIM and the IMC in terms of the rotor speed and position, the grid voltage characteristics, and the power set points. Experimental results are presented from a $5.5 \mathrm{~kW}$ test rig to validate the method.

\section{BACKGROUND}

The primary role of WECS in renewable energy systems is consistent with the continuous development of new topologies. However, research of legacy topologies with modern control strategies also helps to improve the efficient use of electrical energy taking advantage of already installed assets. In this work a well-known configuration for the DFIM, the Scherbius scheme shown in Fig. 1, with a modern power converter topology and control scheme is presented. The IMC is rated to one third of machine power due to the restricted DFIM speed range considered (four-quadrant operation with $\pm 30 \%$ of synchronous speed) [16].

\section{A. Indirect Matrix Converter Model}

The IMC is defined as a two-stage direct AC-AC converter with a virtual DC link. This allows a safe operation using the zero DC link current switching strategy. For the first stage the DC link voltage $v_{d c}$ is calculated using phase voltage vectors $\boldsymbol{v}_{i n}$ and the rectifier switching states $\left[\boldsymbol{S}_{r}\right]$ while input currents $\boldsymbol{i}_{i n}$ use DC link current $i_{d c}$ and $\left[\boldsymbol{S}_{r}\right]^{T}$ as follows:

$$
v_{d c}=\left[\boldsymbol{S}_{r}\right] \boldsymbol{v}_{i n}
$$




$$
\boldsymbol{i}_{\text {in }}=\left[\boldsymbol{S}_{r}\right]^{T} i_{d c}
$$

where

$$
\left[\boldsymbol{S}_{r}\right]=\left[\begin{array}{lll}
S_{r 1}-S_{r 4} & S_{r 3}-S_{r 6} & S_{r 5}-S_{r 2}
\end{array}\right] .
$$

For the second stage the DC link current $i_{d c}$ is calculated using output currents $\boldsymbol{i}_{r}$ and the inverter switching states while the output voltage $\boldsymbol{v}_{r}$ is calculated using the DC link voltage $v_{d c}$ and the corresponding inverter switching states as follows:

$$
\begin{gathered}
i_{d c}=\left[\begin{array}{lll}
S_{i 1} & S_{i 3} & S_{i 5}
\end{array}\right] \boldsymbol{i}_{r} \\
\boldsymbol{v}_{r}=\left[\begin{array}{ccc}
S_{i 1}-S_{i 4} & S_{i 3}-S_{i 6} & S_{i 5}-S_{i 2}
\end{array}\right]^{T} v_{d c} .
\end{gathered}
$$

Some constraints validate the model and enable the converter safe operation, such as avoiding a short circuit on the rectifier input phases as well as an open circuit of the inverter output phases. From all the possible states of the IMC only 72 are allowed, nine for the rectifier and eight for the inverter. However, only three of the nine possible rectifier states are used. The latter to impose a positive DC link voltage, giving a finite set of 24 states.

\section{B. DFIM Dynamic Model}

The DFIM is usually lighter, smaller and cheaper than other generators [6], such as the squirrel cage induction, the synchronous, and the permanent magnet synchronous generator. In a DFIM-based WECS a partial rated power converter is located at the rotor terminals as shown in Fig. 1.

In this paper the DFIM is modeled as an equivalent electrical circuit using equations referred to the $\alpha \beta$ stationary reference frame fixed to the stator. The time-variant-voltage vectors are defined by equations (6) and (7). This equivalent model is preferred since grid interconnection constraints are imposed directly on the stator variables and it simplifies the control variables.

$$
\begin{gathered}
\boldsymbol{v}_{\alpha \beta s}=R_{s} \boldsymbol{i}_{\alpha \beta s}+L_{s} \frac{d}{d t}\left(\boldsymbol{i}_{\alpha \beta s}\right)+L_{m} \frac{d}{d t}\left(\boldsymbol{i}_{\alpha \beta r}^{\prime} e^{j \theta_{r}}\right) \\
\boldsymbol{v}_{\alpha \beta r}^{\prime}=R_{r}^{\prime} \boldsymbol{i}_{\alpha \beta r}^{\prime}+L_{r}^{\prime} \frac{d}{d t}\left(\boldsymbol{i}_{\alpha \beta r}^{\prime}\right)+L_{m} \frac{d}{d t}\left(\boldsymbol{i}_{\alpha \beta s} e^{-j \theta_{r}}\right)
\end{gathered}
$$

with

$$
\begin{gathered}
\boldsymbol{i}_{\alpha \beta r}^{\prime}=I_{r}^{\prime} e^{j \theta_{s l i p}}, I_{r}^{\prime}=I_{r} \frac{N_{r}}{N_{s}} \\
\boldsymbol{v}_{\alpha \beta s}=V_{s} e^{j \theta_{g}}, \boldsymbol{i}_{\alpha \beta s}=I_{s} e^{j\left(\theta_{g}+\theta_{p f}\right)}
\end{gathered}
$$

and

$$
I_{s}=\frac{2}{3} \frac{S}{V_{s}}, S=\sqrt{P^{2}+Q^{2}}, \theta_{p f}=\tan ^{-1}\left(\frac{Q_{s}}{P_{s}}\right) .
$$

\section{Model-Based Predictive Control}

MBPC can be used in the control of power converters, especially those without large energy storage elements. Each sampling instant $k$, the behavior of the system at $k+1$ is predicted using the mathematical model, minimizing the cost function to select the optimal state of the converter. The cost function can contain the prediction error and any other target subject to control. Such targets can be the switching frequency, the input displacement factor to the converter, etc. [30], [31].

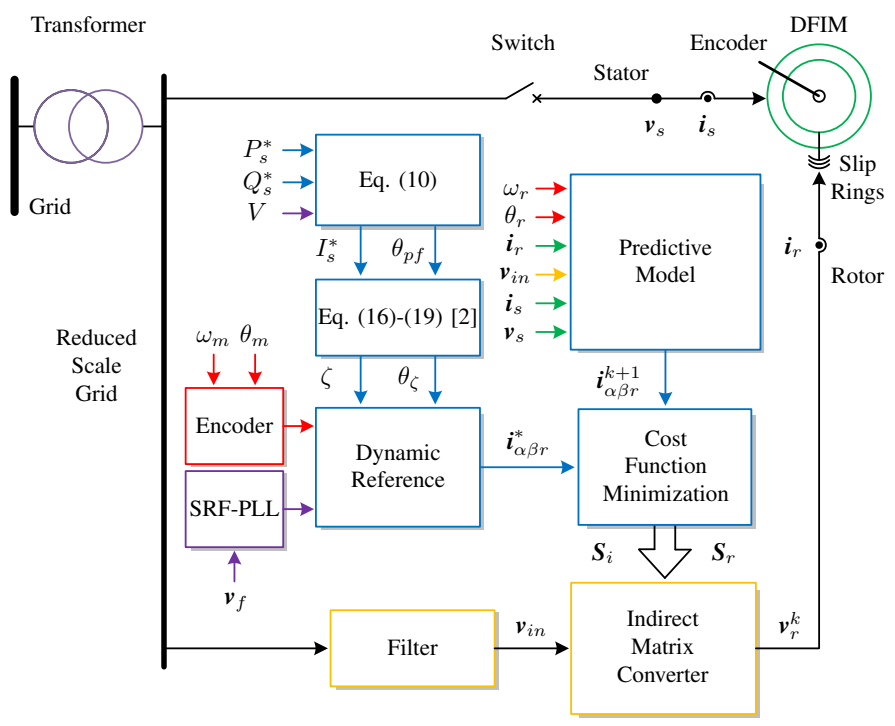

Fig. 2. Block diagram of the indirect power control using predictive rotor current control strategy.

\section{Proposed SCHEME: Indirect Power CONTROL FOR THE DFIM USING MOdEL-BASED PREDICTIVE Rotor CURRENT CONTROL}

The model-based predictive rotor current control, shown in Fig. 2, has been validated in simulation in [32] performing the following tasks.

- Decouple the stator active and reactive power references $P_{s}^{*}, Q_{s}^{*}$ into a stator current reference.

- Integrate the rotor electrical angular frequency $\omega_{r}$ and angle $\theta_{r}$, and the grid voltage amplitude, angular frequency $\omega_{g}$ and angle $\theta_{g}$.

- Develop the dynamic reference of the variable-speed system valid for startup, synchronization and power control as shown in [32].

$$
\begin{gathered}
I_{r}^{*}=\frac{N_{s}}{N_{r}} \frac{\zeta_{\text {mag }}}{L_{m}\left(\omega_{\text {slip }}+\omega_{r}\right)} \\
\theta_{\text {aux }}=\theta_{g}+\theta_{\zeta}-\theta_{r}-\pi / 2
\end{gathered}
$$

- Predict the DFIM rotor currents for a stator-fixed timevarying $\alpha \beta$ reference frame as presented in [10], [11].

$$
i_{\alpha r}^{\prime k+1}=\frac{1}{L_{s} L_{r}^{\prime}-L_{m}^{2}}\left[\begin{array}{l}
L_{s} v_{\alpha r}^{\prime k}\left[v_{\alpha i n}^{k}, S_{r, i}^{k}\right]-L_{m} v_{\alpha s}^{k}- \\
L_{s} R_{r}^{\prime} i_{\alpha r}^{\prime k}+L_{m} R_{s} i_{\alpha s}^{k}- \\
L_{s} L_{r}^{\prime} \omega_{r}^{k} i_{\beta r}^{\prime}{ }^{\prime}-L_{m} L_{s} \omega_{r}^{k} i_{\beta s}^{k}
\end{array}\right] t_{s}+i_{\alpha r}^{\prime k}
$$

$$
i_{\beta r}^{\prime k+1}=\frac{1}{L_{s} L_{r}^{\prime}-L_{m}^{2}}\left[\begin{array}{l}
L_{s} v_{\beta r}^{\prime}\left[v_{\beta i n}^{k}, S_{r, i}^{k}\right]-L_{m} v_{\beta s}^{k}- \\
L_{s} R_{r}^{\prime} i_{\beta r}^{\prime k}+L_{m} R_{s} i_{\beta s}^{k}+ \\
L_{s} L_{r}^{\prime} \omega_{r}^{k} i_{\alpha r}^{\prime k}+L_{m} L_{s} \omega_{r}^{k} i_{\alpha s}^{k}
\end{array}\right] t_{s}+i_{\beta r}^{\prime k}
$$

- Evaluate the rotor current prediction twenty-four times using a cost function. 

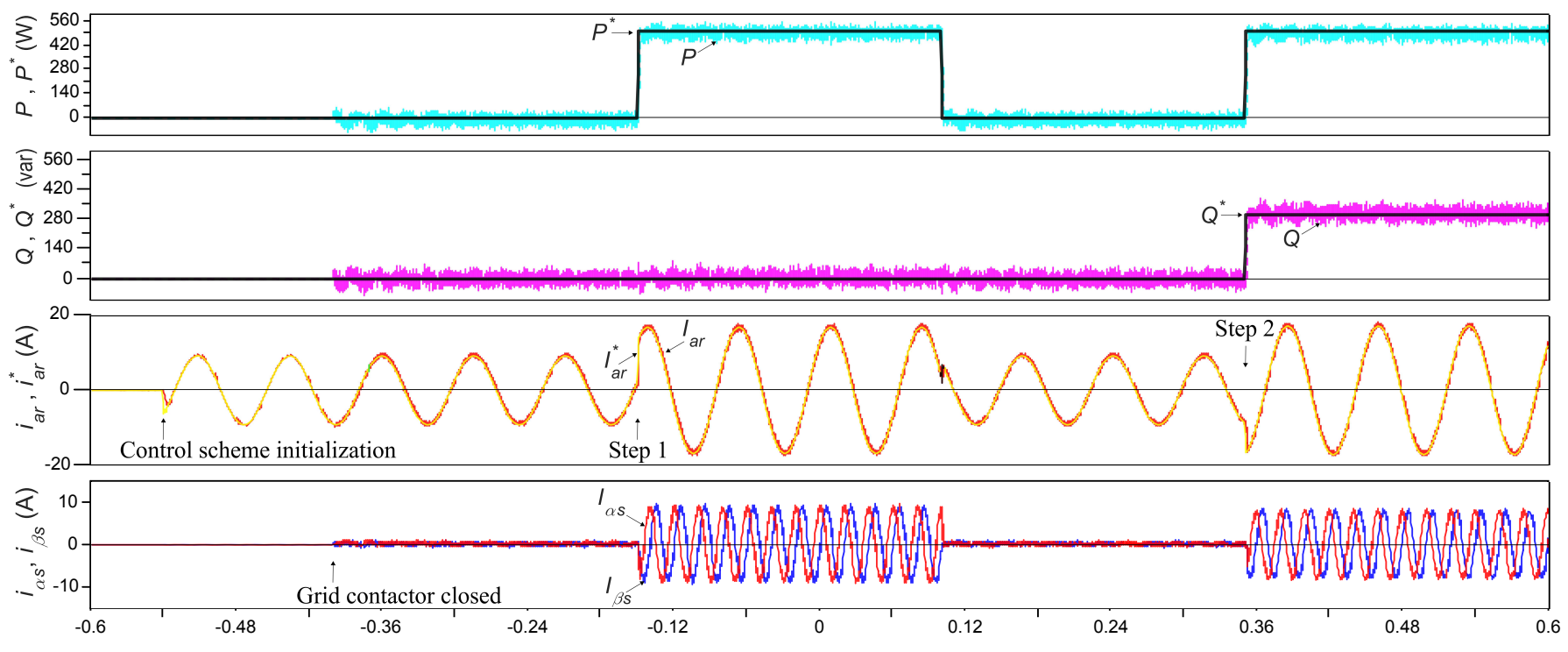

Fig. 3. Rotor and stator currents in three stages: synchronization, active power step, and simultaneous active and reactive power steps at constant shaft speed of $950 \mathrm{rpm}$.

- Apply the optimum switching state of the IMC, implicitly assuming the use of rotor variables referred to the stator (primed).

$$
g^{k+1}=\left|i_{\alpha r}^{*}-i_{\alpha r}^{k+1}\right|+\left|i_{\beta r}^{*}-i_{\beta r}^{k+1}\right|
$$

For a thorough explanation of how the equations (11) to (15) were obtained and how the prediction relation between them works, the reader is encouragingly referred to [10], [11] and [32].

\section{IMPLEMENTATION}

The simulations were carried out with the software GeckoCIRCUITS from Gecko-Research (a spin-off company of ETH Zurich, Switzerland). The experiments were undertaken using a dSPACE DS1103 for data acquisition and rotor current control (setting $P_{s}^{*}$ and $Q_{s}^{*}$ to zero during synchronization), and a Spartan-6 FPGA to provide the converter switching signals using the zero current commutation protocol for the IMC.

\section{A. Simulation Results}

The simulation waveforms shown in Fig. 3 present the expected results for the DFIM used to validate the experimental results. Firstly, achieving the stator voltage synchronization with the grid through power control, applying zero active and zero reactive power. Secondly, a step of $500 \mathrm{~W}$ with 0 var, and finally applying a step of $500 \mathrm{~W}$ with 300 var at the same time. Always imposing constant speed of 950 rpm to the DFIM shaft. As seen in Fig. 3, the rotor current is controlled smoothly, allowing a permissible low ripple in the stator current and consequently in the active and reactive power.

\section{B. Experimental Results}

The setup, shown in Fig. 4, includes: 1.- A $5.5 \mathrm{~kW}$ DFIM with parameters $R_{r}^{\prime}=0.783 \Omega, L_{l r}^{\prime}=10.5 \mathrm{mH}, L_{r}^{\prime}=75$
$\mathrm{mH}, R_{s}=0.718 \Omega, L_{l s}=10.7 \mathrm{mH}, L_{s}=75.2 \mathrm{mH}, L_{m}=$ $64.5 \mathrm{mH}$, stator to rotor turns ratio $N_{s} / N_{r}=1.447$ and pole pairs $P_{p}=4$. 2.- A $10 \mathrm{~kW}$ indirect matrix converter built using bidirectional switches formed by two IGBTs in common collector configuration rated to $600 \mathrm{~V}$ and $80 \mathrm{~A}$. 3.- A LC input filter $L_{f}=10 \mu \mathrm{H}, R_{f}=0.5 \Omega, C_{f}=40 \mu \mathrm{F}$. The reducedscale grid is emulated using two three-phase auto-transformers rated to $3 \mathrm{kVA}$ each with a galvanic-isolation transformer at the output. The system output is limited by the rated power of the reduced grid and by the mechanical power input to the DFIM. In this case a $3 \mathrm{~kW}$ induction motor works as the prime motor driven by a variable frequency drive rated to $3 \mathrm{~kW}$. The whole system is therefore limited to test this control strategy at one third of nominal voltage.

Active and reactive power references are changed using steps from zero to $500 \mathrm{~W}$ and from zero to 300 var. Zero conditions $\left(P_{s}^{*}=0, Q_{s}^{*}=0\right)$ set the stator current reference to $\left|I_{s}^{*}\right|=0 \mathrm{~A}$ and $\theta_{p f}=0^{\circ}$ for equation (10). These parameters establish the synchronization conditions of equal frequency, amplitude, phase and sequence between the stator and the grid as stated in [11].

The rotor current is constantly controlled with the same strategy. The reference is calculated dynamically using the discrete model of the system and the conditions taken from the rotor and the grid. This method selects the optimum switching state $S_{r, i}^{k+1}$ for the IMC to provide the right rotor voltage space vector $\boldsymbol{v}_{r}$, and thus to obtain the least possible error. Therefore, with a precise tracking of the rotor current reference, MBPC will ensure fast grid synchronization and fast response to step references with low ripple as it can be seen in Fig. 6 and Fig. 7 , respectively.

The synchronization process can be seen in Fig. 5. Before grid interconnection the total harmonic distortion of $\boldsymbol{v}_{s}$ is $1.52 \%$. A maximum difference of $30 \mathrm{~V}$ between $\boldsymbol{v}_{s}$ and $\boldsymbol{v}_{g}$ causes an overshoot of only $1.11 \mathrm{~A}$ in the stator currents when the contactor is closed. 


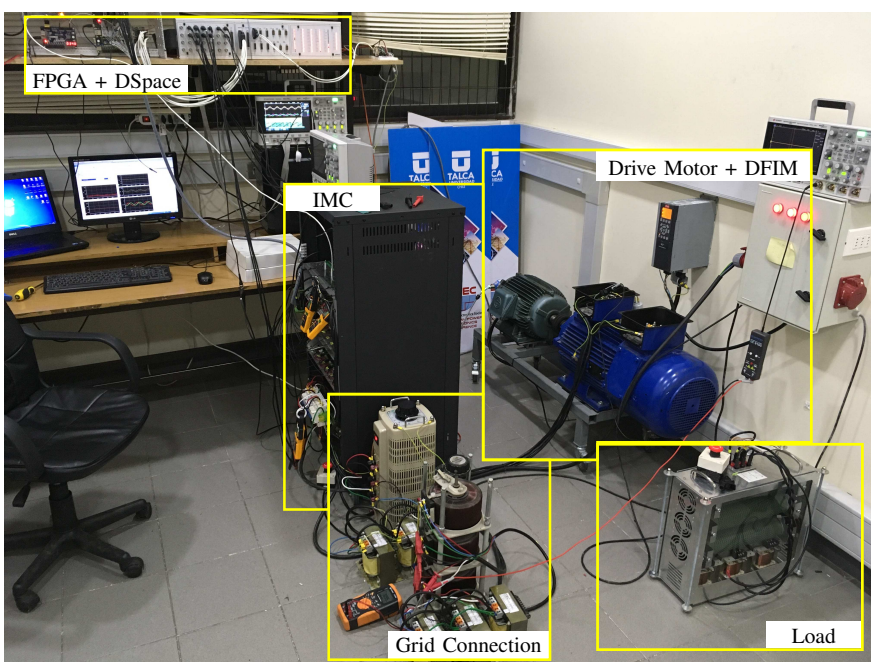

Fig. 4. Experimental test rig.
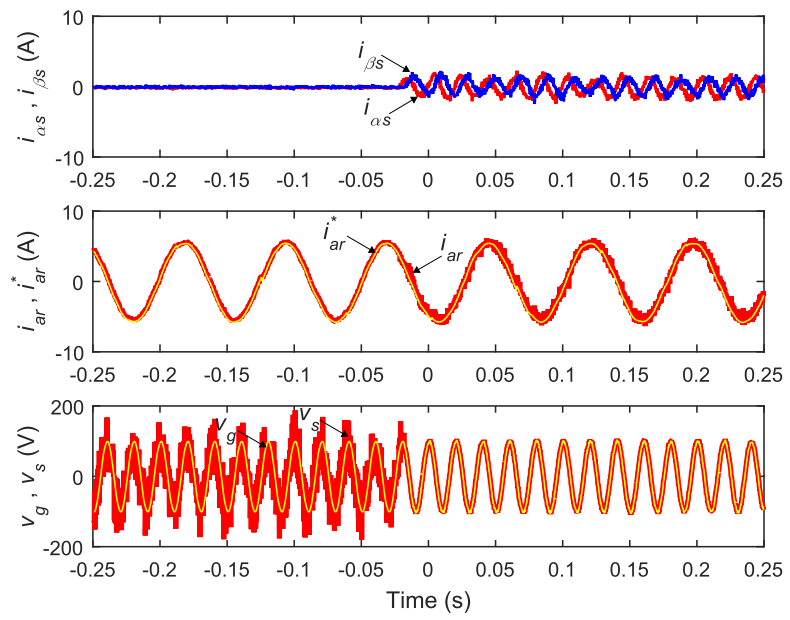

Fig. 5. Stator and rotor current, stator and grid voltage during synchronization at constant speed of $950 \mathrm{rpm}$.
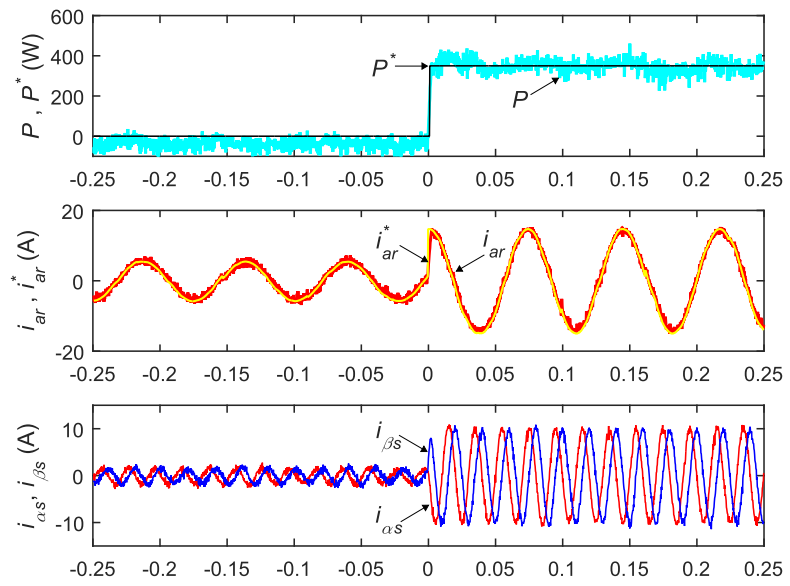

Fig. 6. Rotor current control with step on the active power reference at constant speed of $950 \mathrm{rpm}$.
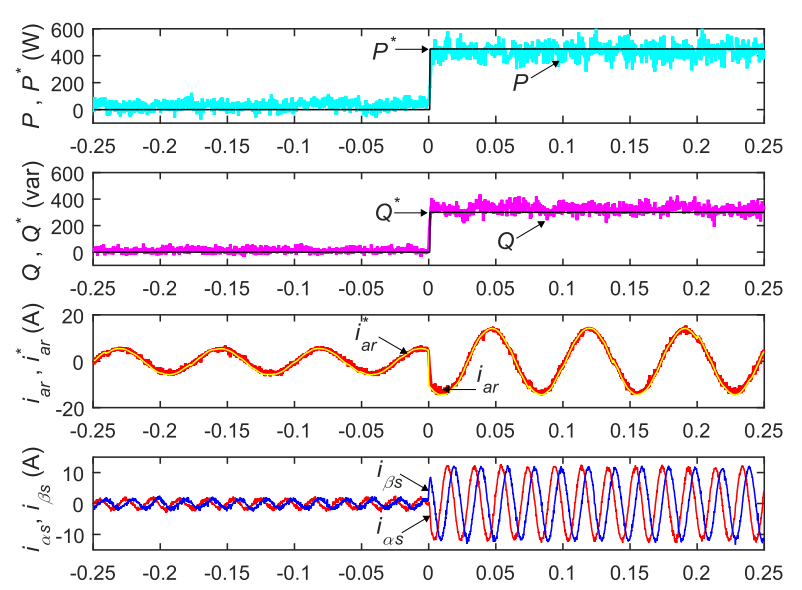

Fig. 7. Rotor current control with step on the active and reactive power reference at constant speed of $950 \mathrm{rpm}$.

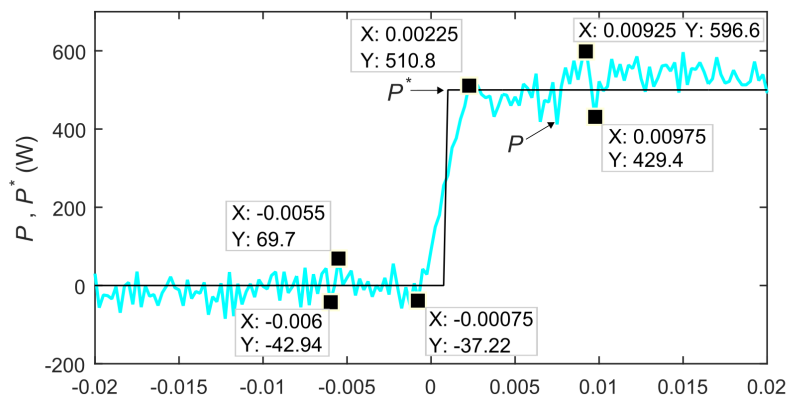

Fig. 8. Close look of the DFIM active power to see the ripple and dynamic response during a step change.

The power references in the experimental results were limited by the element having the smallest power rating. In this case the reference, as shown in Fig. 6, changed from zero to $0.5 \mathrm{~kW}$, and in Fig. 7 from zero to $0.3 \mathrm{kvar}$ plus the same active power as the former. In the middle of Fig. 6, the rotor currents are shown beginning with the synchronization steady state to the corresponding magnitude and phase for the applied power reference. The step changes in the power references were made at the same time as shown in Fig. 7. During the implementation time, the shaft speed of the wind turbine remained steady as $950 \mathrm{rpm}$. In this constant speed condition, the DFIM is operating above the synchronous speed, which is $750 \mathrm{rpm}$ for the 8 -pole $50 \mathrm{~Hz}$ machine used in this work.

Figs. 5 to 7 show the synchronization and power flow control for the DFIM using only one control scheme. As can be seen, it is sufficient to know the grid voltage requirements and set $Q_{s}^{*}=0$ and $P_{s}^{*}=0$ to achieve fast synchronization of the DFIM with the proposed predictive scheme. In this implementation, as well as in previous simulations, grid requirements were fulfilled in two cycles of the rotor current as shown in Fig. 5. The grid contactor closure was made 40 ms after the initialization. As it can be seen in Fig. 8, there is a fast response of $1.5 \mathrm{~ms}$ to the step change in the power 
reference. Analyzing the segment around the step, the average power measured goes from $-38.52 \mathrm{~W}$ to $504.5 \mathrm{~W}$, presenting a maximum ripple of $165.6 \mathrm{~W}$. These results are better to those presented in [22] considering a larger sampling time and the implementation of the method without digital delay compensation.

Moreover, the ripple of active and reactive power is similar for different steps in the reference. The latter leads to better signal-to-noise ratios for higher reference values. The dynamic response is also improved with higher reference values. The rate of change of power over time is $362 \mathrm{~kW} / \mathrm{s}$ for this low scale implementation, but if the scale of the grid is increased, as well as the power rating, it is expected to have a steeper response. In simulation, $1 \mathrm{~kW}$ step in the reference required seven times the sampling time and in this implementation 0.5 $\mathrm{kW}$ required fifteen times the sampling time, proving better dynamic response at higher power flow. This reduced-scale implementation can be considered as the worst-case scenario.

\section{Conclusions}

A novel rotor current control scheme has been proposed in this paper allowing a smooth grid synchronization and fast response to power step commands at variable speed. It is sufficient to know the grid voltage requirements and set $Q_{s}^{*}=0$ and $P_{s}^{*}=0$ to generate a reference for the rotor current and achieve the DFIM synchronization. This predictive scheme controls the rotor current with a sinusoidal reference and maintains sinusoidal stator waveforms to track the active and reactive power references. The latter with a sampling time of $100 \mu \mathrm{s}$ and one third of grid voltage for the converter. It is sufficient to change the reference value for $P$ and $Q$ to consequently change the operational point of the machine by adapting the dynamic references of $I_{r}$ and $\theta_{\text {aux }}$ to control the rotor current. Future work will present this MBPC-DFIMIMC configuration as part of a resilient AC microgrid with capability of operating in both islanded and grid-connected modes.

\section{REFERENCES}

[1] International Energy Agency, Key World Energy Statistics 2020. IEA Publications, 2020. [Online]. Available: https://www.oecd-ilibrary.org/content/publication/295f00f5-en

[2] J. L. Elizondo, M. Rivera, and P. Wheeler, "Wind energy development and technology in the world: A brief overview," in 2019 IEEE CHILEAN Conference on Electrical, Electronics Engineering, Information and Communication Technologies (CHILECON), November 2019, pp. 1-5.

[3] V. Yaramasu, B. Wu, P. C. Sen, S. Kouro, and M. Narimani, "Highpower wind energy conversion systems: State-of-the-art and emerging technologies," Proceedings of the IEEE, vol. 103, no. 5, pp. 740-788, May 2015.

[4] S. Toledo, M. Rivera, and J. L. Elizondo, "Overview of wind energy conversion systems development, technologies and power electronics research trends," in 2016 IEEE International Conference on Automatica (ICA-ACCA), October 2016, pp. 1-6.

[5] M. Liserre, R. Cardenas, M. Molinas, and J. Rodriguez, "Overview of multi-mw wind turbines and wind parks," Industrial Electronics, IEEE Transactions on, vol. 58, no. 4, pp. 1081-1095, April 2011.

[6] R. Cardenas, R. Pena, S. Alepuz, and G. Asher, "Overview of control systems for the operation of dfigs in wind energy applications," Industrial Electronics, IEEE Transactions on, vol. 60, no. 7, pp. 2776-2798, July 2013
[7] P. W. Wheeler, J. Rodriguez, J. C. Clare, L. Empringham, and A. Weinstein, "Matrix converters: a technology review," Industrial Electronics, IEEE Transactions on, vol. 49, no. 2, pp. 276-288, April 2002.

[8] R. Cardenas, R. Pena, P. Wheeler, J. Clare, and G. Asher, "Control of the reactive power supplied by a wecs based on an induction generator fed by a matrix converter," Industrial Electronics, IEEE Transactions on, vol. 56, no. 2, pp. 429-438, Feb 2009.

[9] J. Rodriguez, M. Rivera, J. W. Kolar, and P. W. Wheeler, "A review of control and modulation methods for matrix converters," Industrial Electronics, IEEE Transactions on, vol. 59, no. 1, pp. 58-70, Jan 2012.

[10] M. Rivera, J. L. Elizondo, M. E. Macias, O. M. Probst, O. M. Micheloud, J. Rodriguez, C. Rojas, and A. Wilson, "Model predictive control of a doubly fed induction generator with an indirect matrix converter," in IECON 2010 - 36th Annual Conference on IEEE Industrial Electronics Society, November 2010, pp. 2959-2965.

[11] J. L. Elizondo, A. Olloqui, M. Rivera, M. E. Macias, O. Probst, O. M. Micheloud, and J. Rodriguez, "Model-based predictive rotor current control for grid synchronization of a dfig driven by an indirect matrix converter," IEEE Journal of Emerging and Selected Topics in Power Electronics, vol. 2, no. 4, pp. 715-726, December 2014.

[12] Y. Sun, X. Li, M. Su, H. Wang, H. Dan, and W. Xiong, "Indirect matrix converter-based topology and modulation schemes for enhancing input reactive power capability," Power Electronics, IEEE Transactions on, vol. 30, no. 9, pp. 4669-4681, September 2015.

[13] R. Cardenas, R. Pena, P. Wheeler, and J. Clare, "Reactive power capability of wecs based on matrix converter," Electronics Letters, vol. 44, no. 11, pp. 674-676, May 2008.

[14] IEEE Std 1547, IEEE Approved Draft Standard for Interconnection and Interoperability of Distributed Energy Resources with Associated Electric Power Systems Interfaces - Amendment 1 to IEEE Std 15472018 to provide more flexibility for adoption of abnormal operating performance Category III, IEEE Std., March 2020.

[15] E. Tremblay, S. Atayde, and A. Chandra, "Comparative study of control strategies for the doubly fed induction generator in wind energy conversion systems: A dsp-based implementation approach," Sustainable Energy, IEEE Transactions on, vol. 2, no. 3, pp. 288-299, July 2011.

[16] R. Pena, J. C. Clare, and G. M. Asher, "Doubly fed induction generator using back-to-back pwm converters and its application to variable-speed wind-energy generation," Electric Power Applications, IEE Proceedings -, vol. 143, no. 3, pp. 231-241, May 1996.

[17] R. Cardenas, R. Pena, P. Wheeler, J. Clare, A. Munoz, and A. Sureda, "Control of a wind generation system based on a brushless doubly-fed induction generator fed by a matrix converter," Electric Power Systems Research, vol. 103, no. 0, pp. 49-60, October 2013.

[18] G. Abad, M. A. Rodriguez, G. Iwanski, and J. Poza, "Direct power control of doubly-fed-induction-generator-based wind turbines under unbalanced grid voltage," Power Electronics, IEEE Transactions on, vol. 25, no. 2, pp. 442-452, February 2010.

[19] A. Petersson, L. Harnefors, and T. Thiringer, "Evaluation of current control methods for wind turbines using doubly-fed induction machines," Power Electronics, IEEE Transactions on, vol. 20, no. 1, pp. 227-235, January 2005.

[20] R. Datta and V. T. Ranganathan, "Direct power control of grid-connected wound rotor induction machine without rotor position sensors," Power Electronics, IEEE Transactions on, vol. 16, no. 3, pp. 390-399, May 2001.

[21] M. Shahroozi, R. Ghobadi, and A. Radan, "Using virtual direct power control for synchronizing dfig with grid," in Power Electronics, Drive Systems and Technologies Conference (PEDSTC), 2014 5th, February 2014, pp. 96-101.

[22] J. Hu, J. Zhu, Y. Zhang, G. Platt, Q. Ma, and D. Dorrell, "Predictive direct virtual torque and power control of doubly fed induction generators for fast and smooth grid synchronization and flexible power regulation," Power Electronics, IEEE Transactions on, vol. 28, no. 7, pp. 3182-3194, July 2013.

[23] Y. Zhang, J. Jiao, D. Xu, D. Jiang, Z. Wang, and C. Tong, "Model predictive direct power control of doubly fed induction generators under balanced and unbalanced network conditions," Industry Applications, IEEE Transactions on, vol. 56, no. 1, pp. 771-786, January 2020.

[24] Y. Zhang, T. Jiang, and J. Jiao, "Model-free predictive current control of dfig based on extended state observer under unbalanced and distorted grid," Power Electronics, IEEE Transactions on, vol. 35, no. 8, pp. 81308139, August 2020.

[25] C. Cheng, P. Cheng, H. Nian, and D. Sun, "Model predictive stator current control of doubly fed induction generator during network unbalance," IET Power Electronics, vol. 11, no. 1, pp. 120-128, March 2018. 
[26] G. F. Gontijo, T. C. Tricarico, B. W. Frana, L. F. da Silva, E. L. van Emmerik, and M. Aredes, "Robust model predictive rotor current control of a dfig connected to a distorted and unbalanced grid driven by a direct matrix converter," Sustainable Energy, IEEE Transactions on, vol. 10, no. 3, pp. 1380-1392, July 2019.

[27] T. Friedli and J. W. Kolar, "Milestones in matrix converter research," IEEJ Journal of Industry Applications, vol. 1, no. 1, pp. 2-14, July 2012.

[28] S. Vazquez, J. Rodriguez, M. Rivera, L. G. Franquelo, and M. Norambuena, "Model predictive control for power converters and drives: Advances and trends," Industrial Electronics, IEEE Transactions on, vol. 64, no. 2, pp. 935-947, February 2017.

[29] T. Dragicevic, "Model predictive control of power converters for robust and fast operation of ac microgrids," Power Electronics, IEEE Transactions on, vol. 33, no. 7, pp. 6304-6317, July 2018.

[30] M. Rivera, A. Wilson, C. A. Rojas, J. Rodriguez, J. R. Espinoza, P. W. Wheeler, and L. Empringham, "A comparative assessment of model predictive current control and space vector modulation in a direct matrix converter," Industrial Electronics, IEEE Transactions on, vol. 60, no. 2, pp. 578-588, February 2013

[31] F. Villarroel, J. R. Espinoza, C. A. Rojas, J. Rodriguez, M. Rivera, and D. Sbarbaro, "Multiobjective switching state selector for finite-states model predictive control based on fuzzy decision making in a matrix converter," Industrial Electronics, IEEE Transactions on, vol. 60, no. 2, pp. 589-599, February 2013.

[32] A. Olloqui, J. L. Elizondo, M. Rivera, M. E. Macias, O. M. Micheloud, R. Pena, and P. Wheeler, "Indirect power control of a dfig using modelbased predictive rotor current control with an indirect matrix converter," in 2015 IEEE International Conference on Industrial Technology (ICIT), March 2015, pp. 2275-2280.

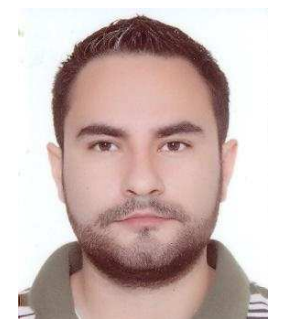

Alejandro Olloqui (S'10) was born in Querétaro, México, in 1986. He received the B.Sc. degree in Mechatronics from Tecnológico de Monterrey (ITESM), Laguna Campus, Torreón, México, in 2008, and the M.Sc. degree in Electronic Systems Engineering from ITESM, Monterrey Campus, Monterrey, México, in 2011, where he is currently pursuing his $\mathrm{Ph} . \mathrm{D}$. degree with the School of Engineering and Sciences.

He was a full-time electrical engineer at Siemens Gamesa Renewable Energy, México, from 20162019, and currently is a full-time senior electrical engineer at Vestas, México, since 2019.

M.Sc. Olloqui current research interests include control of power converters, adjustable-speed drives, renewable energy technologies, and grid-connected wind energy conversion systems.

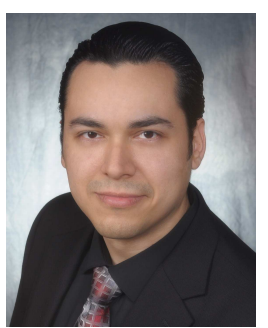

José L. Elizondo (S'07-M'12-SM'18) was born in Reynosa, Tamaulipas, México, in 1981. He received the B.Sc., M.Sc., and Ph.D. degrees in Electronic Systems Engineering from Tecnológico de Monterrey (ITESM), Monterrey Campus, México, in 2004, 2007 and 2011, respectively. He served as part-time professor and researcher at the Department of Electrical and Computer Engineering, at ITESM, Monterrey Campus, from 2007 to 2011 and 2014.

$\mathrm{He}$ has carried out research internships and industrial courses regarding power electronics for renewable energy technologies at Universidad Técnica Federico Santa María, in Valparaíso, Chile, at Aalborg University, in Aalborg, Denmark, and at Universidad de Talca, in Curicó, Chile, in 2009, 2011, 2014 and 2016, respectively. Since 2012 he has been working full-time as maintenance engineer and technology consultant at Petróleos Mexicanos (PEMEX) Exploration and Production, in Reynosa.

Dr. Elizondo has been recognized by the IEEE with the Senior Member Grade Elevation in 2018, on the basis of significant performance in the oil and gas industry and research networking on power electronics for renewable energy technologies with the academia. His main research interests include Model-Based Predictive Control, Power Electronic Converters and Renewable Energy Conversion Systems.

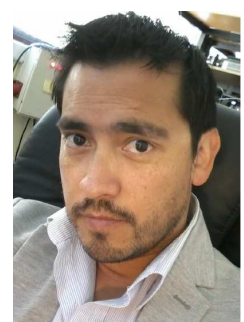

Marco Rivera (S'09-M'11-SM'17) was born in Talca, Chile, in 1982. He received the B.Sc. degree in electronics engineering and the M.Sc. degree in electrical engineering from the Universidad de Concepción, Concepción, Chile, in 2007 and 2008, respectively, and the Ph.D. degree from the Department of Electronics Engineering, Universidad Técnica Federico Santa María, Valparaíso, Chile, in 2011

Since 2013 is with the Energy Conversion and Power Electronics Research Group at the Universidad de Talca. He is currently a Full Professor with the Department of Electrical Engineering at the Universidad de Talca, Curicó, Chile. His main research areas include matrix converters, predictive and digital controls for high-power drives, four-leg converters, and the development of high-performance control platforms based on field-programmable gate arrays.

Prof. Rivera was recipient of the Best $\mathrm{PhD}$ Thesis Award 2012, award given by the Chilean Academy of Science for PhD thesis developed in 2011 by national and foreign students in any Exact or Nature Sciences Program in Chile. In August 2015, Prof. Rivera was awarded with the Outstanding Engineer 2015 Award of the Electrical-Electronics Industry Association and the IEEE-Chile Section. He has received the Second Prize Paper Award in the 2015 IEEE Journal of Emerging and Selected Topics in Power Electronics, and the Best Paper Award in the 2018 IEEE Transactions on Industrial Electronics.

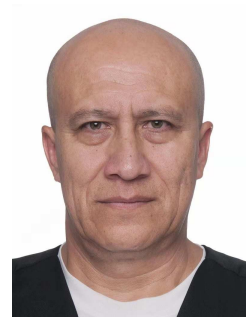

Manuel E. Macías received the B.Sc. degree in electronics and communications engineering from Tecnológico de Monterrey (ITESM), Monterrey Campus, México, in 1987, and the Ph.D. degree in power electronics from the Technical University of Dresden, Dresden, Germany, in 1994.

He is currently a Research Professor at the School of Science and Engineering of the Tecnológico de Monterrey, Monterrey Campus, where he has designed and implemented laboratories for Industrial Electronics, Electrical Drives, Automation, Virtual Instrumentation, and Tele-Engineering, and has leaded research projects on solid state converters, predictive and vector control, power theories and power electronics. He also leads initiatives on Computer-Assisted Learning and Virtual and Remote Environments to enhance training and distance learning in engineering. He has developed several Remote Labs platforms to build a Collaborative Intercampus Remote Labs Network and coordinates a CyberPhysical Labs initiative for automation and industrial networks to equip 15 Campuses all over México.

Dr. Macías has published more than 40 technical publications on international conferences and specialized journals, has advised more than 20 Master thesis (M.Sc.) and doctoral thesis (Ph.D.) and has two patents in process for Remote Labs Platforms, one patent in China and one international patent. His major research interests are Automation, Power Electronics, Electrical Drives and Innovation and Technology in Engineering Education. 


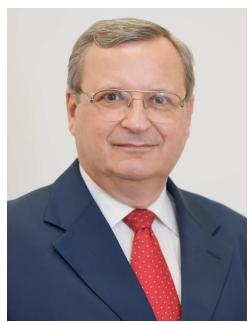

Osvaldo M. Micheloud (M'97-SM'13) was born in Argentina; he graduated in Electrical Engineering from University of Rosario, Argentina, in 1973. He obtained his M.Sc. in 1978, and his Ph.D. in 1979, both in the area of Electronics and Automatic Control from the University of Washington, Seattle, USA.

After 20 years of international industrial experience, in 1997, he became full-time Professor and head of the Department of Electronics Engineering at Instituto Tecnológico de Buenos Aires, ITBA. In 1998, he was appointed Vice Rector for Academic Affairs. In 2006 he joined, as visiting professor, the Department of Electrical Engineering at Tecnológico de Monterrey, Monterrey Campus, México, and soon after in this position he was appointed full professor and director of the Master Program in Energy Engineering.

Dr. Micheloud received the Teaching and Research Award and was named Roberto Rocca Endowed Research Chair Professor in 2009 for his contributions to academic activities in Monterrey. In 2013, he received the Rómulo Garza Prize for his contributions to develop applied research linked with the needs of the Mexican Industrial Sector. He was the founder and has served as its first Director of the Industrial Consortium to Foster Applied Research for Economic Growth for 11 years at Tecnológico de Monterrey, Nuevo León, México. He is part of México's National Researchers System (level I) and maintains a large network of collaborations with industrial companies, former students, entrepreneurs, and researchers. In 2019 he retired from Tecnológico de Monterrey and currently he works as an independent consultant engineer in Argentina.

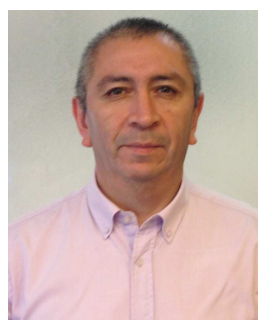

Rubén Peña (S'95-M'97-SM'16) was born in Coronel, Chile. He received the B.Sc. degree in electrical engineering from the University of Concepción, Concepción, Chile, in 1984, and the M.Sc. and Ph.D. degrees in electrical and electronics engineering from the University of Nottingham, Nottingham, U.K., in 1992 and 1996, respectively.

From 1985 to 2008, he was a Lecturer with the University of Magallanes, Punta Arenas, Chile. He has been with the Department of Electrical Engineering, University of Concepción, since 2008, where he is currently a Full Professor. His research interests include control of power electronic converters, ac drives, and renewable energy systems.

Dr. Peña received the Best Paper Award from the IEEE TRANSACTIONS ON INDUSTRIAL ELECTRONICS, in 2004, and the Ramón Salas Edward Award for research excellence from the Chilean Institute of Engineers, in 2009.

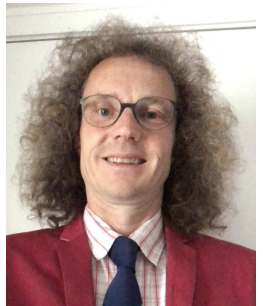

Patrick Wheeler (M'01-SM'10) received the B.Eng. (Hons.) degree in electrical engineering from the University of Bristol, Bristol, U.K., in 1990, and the $\mathrm{Ph} . \mathrm{D}$. degree in electrical engineering for his work on matrix converters from the same university, in 1994.

In 1993, he moved to the University of Nottingham and worked as a Research Assistant with the Department of Electrical and Electronic Engineering. In 1996, he became a Lecturer in the Power Electronics, Machines, and Control Group, at University of Nottingham, U.K. Since January 2008, he has been a Full Professor with the same research group. From 2015 to 2018, he was the Head of the Department of Electrical and Electronic Engineering, at University of Nottingham.

Prof. Wheeler is currently the Head of the Power Electronics, Machines, and Control Research Group, Global Director of the University of Nottingham's Institute of Aerospace Technology, and is the Li Dak Sum Chair Professor in electrical and aerospace engineering. He has authored and coauthored 500 academic publications in leading international conferences and journals, he is a member of the PELS AdCom and was an IEEE PELS Distinguished Lecturer from 2013 to 2017. 